\title{
Influence of medium constituents on the biosynthesis of cephalosporin-C
}

\author{
Vinod Kumar Nigam* \\ Birla Institute of Scientific Research Statue Circle \\ Jaipur, Rajasthan 302001, India \\ Tel: 911412385283 \\ Fax: 911412385121 \\ E-mail: nigam_vinod@yahoo.com

\section{Ruchi Verma} \\ Birla Institute of Scientific Research Statue Circle \\ Jaipur, Rajasthan 302001, India \\ Tel: 911412385283 \\ Fax: 911412385121 \\ E-mail: verma_ruchi03@rediffmail.com
}

\section{Abhishek Kumar}

Birla Institute of Scientific Research Statue Circle Jaipur, Rajasthan 302001, India

Tel: 911412385283

Fax: 911412385121

\section{Subir Kundu}

School of Biochemical Engineering

Institute of Technology

Banaras Hindu University

Varanasi, Uttar Pradesh 221005 India

Tel: 915422367829

Fax: 915422368693

E-mail: subirbhu@gmail.com

\section{Purnendu Ghosh}

Birla Institute of Scientific Research Statue Circle Jaipur, Rajasthan 302001, India

Tel: 911412385283

Fax: 911412385121

E-mail: pghosh9@yahoo.com

Financial support: Department of Science and Technology, Government of India for carrying out this work.

Keywords: Acremonium chrysogenum, batch fermentation, cephalosporin-C, methionine, stirred tank bioreactor.

Abbreviations: $\quad$ CPC: cephalosporin-C

STBR: stirred tank bioreactor

Acremonium chrysogenum NCIM 1069 was used for the biosynthesis of cephalosporin-C (CPC) in batch mode of cultivation. The effect of different medium constituents for better yield of CPC was thoroughly investigated. From the results of the fermentation, it was found that ammonium sulphate as inorganic nitrogen source and methionine at the concentration of $0.4 \%$ are most suitable for higher yield of antibiotic. The variation in the $\mathrm{C} / \mathrm{N}$ ratio on the biosynthesis of $\mathrm{CPC}$ showed that a $\mathrm{C} / \mathrm{N}$ ratio of 8.0 is most suitable for maximum production of CPC.
Cephalosporins together with penicillin belong to the family of $\beta$-lactam antibiotics. Cephalosporins are important broad-spectrum antibiotics in the international market and are more resistant to $\beta$-lactamases than penicillins. Cephalosporin-C (CPC), the starting material used for the synthesis of various cephalosporins is produced by aerobic fermentation using different strains of Cephalosporium acremonium and by streptomyces species like Streptomyces clavuligerus. The CPC has a weak antibacterial activity, but the modification of its side chain generates semisynthetic cephalosporins having diversified

*Corresponding author 
antibacterial activity. The mold is recently renamed as Acremonium chrysogenum (Brakhage, 1998; Demain and Zhang, 1998; Silva et al. 1998; Schmitt et al. 2004; Tollnick et al. 2004). The beta-lactam antibiotics particularly penicillin and cephalosporins share approximately $65 \%$ of worldwide market of antibiotics (Elander, 2003). A number of reports are available on the various aspects of CPC production such as production in batch as well in continuous mode using free and immobilized cells of mold, and modes of bioreactor operation etc. (Srivastava and Kundu, 1999; Cruz et al. 2001; Ellaiah et al. 2002; Kundu et al. 2003; Cruz et al. 2004; Kim et al. 2005). The optimization of media components for CPC biosynthesis has been reported by few authors (Shen et al. 1984; Demain and Vaishnav, 2006) and different hypothesis has been proposed. Some of them have investigated the effect of a single constituent on the fermentation of CPC. We have investigated the influence of medium constituents (such as inorganic nitrogen sources, methionine etc.) on the production of CPC in detail. We have also optimized the carbon nitrogen ratio on the biosynthesis of CPC using Acremonium chrysogenum. Such kinds of studies are, nonetheless, very important to secure good production performance.

The biosynthesis of CPC is studied in a 2L-stirred tank bioreactor (STBR) using synthetic medium at optimal conditions. It was observed that with the progress of fermentation increase in the viscosity of broth occurs and thereby decreasing oxygen mass transfer. In our earlier communication, we have attempted to increase the oxygen transfer rate to the broth by coimmobilizing mold with algae called Chlorella pyrenoidosa in a symbiotic mode (Kundu et al. 2003). We have also studied the morphological differentiation and effect of seed of different age on the production of CPC (Verma et al. 2006).

The present paper deals with the optimization of different medium constituents for the increase in biosynthesis of CPC. A comparison of the findings of shake flask and bioreactor studies has also been made for better understanding of the CPC production process.

\section{MATERIALS AND METHODS}

\section{Organism}

The production of CPC was carried out by A. chrysogenum NCIM 1069, obtained from National Chemical Laboratory, Pune, India. The culture was maintained on potatodextrose-agar (PDA) after incubation for 7 days at $\mathrm{pH} 7.2$ and temperature $28^{\circ} \mathrm{C}$.

\section{Culture medium and conditions}

The culture was propagated in the seed medium containing $\left(\mathrm{gL}^{-1}\right)$ sucrose, 30; potassium dihydrogen orthophosphate, 1.5; magnesium sulphate, 0.3 ; and trace metal solution 15 $\mathrm{mL}$ which was sterilized separately (Srivastava et al. 1996).
The trace metal solution contained $\left(\mathrm{gL}^{-1}\right)$ ferrous ammonium sulphate, 0.15; magnesium sulphate, 0.367; calcium chloride, 0.075; zinc sulphate, 0.03; manganese sulphate, 0.03; and copper sulphate 0.008 . The culture was grown in the seed medium for $6-7$ days at $28^{\circ} \mathrm{C}$ in an orbital shaker set at $200 \mathrm{rpm}$.

Batch fermentations were carried out in shake flask and in a STBR at $28^{\circ} \mathrm{C}$ for $144 \mathrm{hrs}$ on the synthetic production medium. The production medium contained $\left(\mathrm{gL}^{-1}\right)$ sucrose, 30; ammonium sulphate, 7.5 ; dipotassium hydrogen orthophosphate, 15.6; potassium dihydrogen orthophosphate, 15.3; DL-methionine, 3.0; sodium sulphate, 1.7 and oleic acid, 1.5. The $\mathrm{pH}$ of the medium was adjusted to 7.2 before sterilization.

The effects of various media constituents at different concentrations were studied and the production of CPC was monitored at shake flask level.

Five different inorganic nitrogen sources (ammonium sulphate, ammonium nitrate, potassium nitrate, sodium nitrate, and ammonium chloride respectively) were selected and their concentration were varied (keeping the total nitrogen concentration almost constant) to observe the effect on the yield of CPC.

The effect of methionine on the production of CPC was investigated by varying its concentration in the synthetic production medium in the range of $3.0 \mathrm{~g} / \mathrm{L}$ to $5.0 \mathrm{~g} / \mathrm{L}$, keeping all other parameters constant.

In order to investigate the effect of $\mathrm{C} / \mathrm{N}$ ratio on the biosynthesis of $\mathrm{CPC}$, the concentration of sucrose was varied keeping the concentration of ammonium sulphate (as nitrogen source) constant. All other fermentation parameters of shake flask studies were kept constant (rpm 200 , temperature $28^{\circ} \mathrm{C}$ and time of fermentation $144 \mathrm{hrs}$ ).

\section{Inoculum}

The surface growth from a 7-days old slant was suspended in $5 \mathrm{~mL}$ of sterile distilled water and was used to inoculate the seed medium.

\section{Cultivation in STBR}

After optimization of various media constituents, batch studies of CPC production was performed at shake flask and bioreactor level $(2.0 \mathrm{~L}$ capacity, Infors A.G. Switzerland, working volume $1.2 \mathrm{~L}$ ) at optimal conditions. The samples were aseptically withdrawn at certain time intervals and analyzed for sucrose, CPC and dry cell weight. Sterile air was passed to the bioreactor for aeration and the temperature inside the vessel was maintained at $28^{\circ} \mathrm{C}$ by cooling water passing through the jacket. The $\mathrm{pH}$ of the broth was maintained at 7.2 using $2 \mathrm{M} \mathrm{KOH}$ and $2 \mathrm{~N}$ $\mathrm{HCl}$. The DO was maintained above $30 \%$ saturation by aeration and agitation. 


\section{Analysis}

The residual sucrose was estimated after hydrolysis by DNS method (Miller, 1959). The method of Boxer and Everett (Boxer and Everett, 1949) was used for the estimation of CPC. Bioassay technique was also conducted for estimation of CPC using Alcaligenes faecalis NCIM 2105 as a test organism. The dry cell weight was estimated by centrifuging $10 \mathrm{~mL}$ of fermentation broth, washed twice with distilled water, recentrifuged and kept for drying at $80^{\circ} \mathrm{C}$ till the constant weight.

\section{RESULTS}

\section{Effect of different inorganic nitrogen sources on the biosynthesis of CPC}

Figure 1, Figure 2, Figure 3, Figure 4 and Figure 5 show the findings of the effect of different inorganic nitrogen sources on the biosynthesis of CPC. It has been observed that the ammonium sulphate, when used as nitrogen source increases the production of CPC in comparison to other inorganic nitrogen sources. The increase in dry cell weight was also noticed. Potassium nitrate also gave good yield of CPC followed by ammonium nitrate. The minimum concentration of CPC was found with ammonium chloride as nitrogen source.

\section{Effect of DL methionine on the biosynthesis of CPC}

The results of the effect of different concentrations of methionine are presented in Figure 6. It is observed that the production of CPC increases with increase in the methionine concentration up to $4.0 \mathrm{~g} / \mathrm{L}$ and thereafter started decreasing. It has been reported that methionine at certain level (optimum concentration) stimulates the differentiation of mold and increases the yield of CPC. Hence, in subsequent studies the optimum concentration of methionine used is $0.4 \%$.

\section{Effect of $\mathrm{C} / \mathrm{N}$ ratio on the biosynthesis of CPC}

The results of this experiment are given in Figure 7. It is clear from the figure that production of CPC increase from $\mathrm{C} / \mathrm{N}$ ratio 5.33 to 8.0 and then decreased. The decreased yield of CPC at higher $\mathrm{C} / \mathrm{N}$ ratio is due to accumulation of sucrose in the broth, which may likely inhibiting the synthesis of enzymes responsible for the formation of CPC.

\section{Batch fermentation of CPC}

It has been observed that the growth rate of mold started increasing after two days of fermentation and the maximum rate of cell mass was formed at around 72-96 hrs, after that the rate of cell mass formation decreased. The formation of CPC initially is low but the production increases steadily at the end of late exponential phase and reached to the maximum value at the stationary phase (Table 1). This evidently reflects that the production of CPC occurs at the late hrs of fermentation, i.e. idiophase. The production of $\mathrm{CPC}$ at bioreactor level was higher $(0.69 \mathrm{mg} / \mathrm{mL})$ as compared to shake flask $(0.53 \mathrm{mg} / \mathrm{mL})$. This increased production of CPC in bioreactor is because of aeration, better mixing and control of $\mathrm{pH}$ and dissolved oxygen (D.O.). A comparative evaluation of different biochemical process parameters of CPC production in shake flask and bioreactor is represented in Table 2 .

\section{DISCUSSION}

Antibiotics are the secondary metabolites produced by the microbes. The biosynthesis of antibiotics i.e. the secondary metabolite is not associated with the growth of mold. In microbial cultures, the production of secondary metabolites and growth related functions do not occur simultaneously. It has been observed that during the production of secondary metabolites, the cell biomass of microbes increases initially and after certain time, it becomes constant/decreases slightly. An increase in the viscosity of the medium is also observed decreasing the oxygen transfer rate. Production varies with the constituents of the media and the stage of the culture development. The secondary metabolites accumulate only after the growth phase (tropophase) i.e. when the culture attains a specific growth rate. Secondary metabolites are often called "idiolites" since they are produced in the "idiophase".

This investigation on the biosynthesis of CPC was attempted with an aim to increase its production as it is a very important beta lactam antibiotic with a broad-spectrum activity. A thorough literature review was performed and it was noticed that though a number of highly productive strains and a number of different strategies have been used for better yield, not much attention has been given in the constituents of synthetic medium used for its biosynthesis. In addition, a number of other reports are available on the production of CPC using complex medium.

When different inorganic nitrogen sources were added to the synthetic production medium, it has been found that only a few are used by mold for maximum synthesis of CPC. Others are not utilized by mold at the same extent. Ammonium sulphate was observed to be the best source of inorganic nitrogen for the higher production of CPC. High content of nitrogen is found to decrease the production. It might be due to the reason that it interferes to the process of differentiation of mycelium to swollen hyphal fragments and arthrospores during the production stage. Production of CPC by many strains of $C$. acremonium is known to be stimulated by the addition of the amino acid methionine. Although methionine can supply sulphur to CPC biosynthetic pathway, this is not the sole mechanism of its stimulatory effect, since norleucine, a non-sulphur analogue also has similar effect. Two other compounds such as DLmethionine-DL-sulfoxide and S-methyl-L-cysteine were reported to be active towards CPC production (Demain and Newkirk, 1962). The methionine stimulates the synthesis of CPC by playing a role in differentiation process. Queener 
and Ellis (Queener and Ellis, 1975) observed the effect of methionine concentrations during the formation of unicellular arthrospores while attempting the production of CPC in complex medium. They have observed that at higher concentration, the percentage of unicellular arthrospores increased from $55 \%$ to $80 \%$ and CPC production is decreased to $85 \%$ of that obtained with normal DL-methionine level. Similarly the role of methionine in CPC synthesis by Acremonium chrysogenum is investigated where the authors have proved that methionine plays a direct role by supplying sulphur for the formation of cephalosporins. Enzymatic and genetic studies of methionine have revealed that it induces four of the enzymes of CPC biosynthesis at the level of transcription. It is also converted to cysteine, one of three precursors of $\mathrm{CPC}$, by cystathionine-gamma-lyase. The main effect of methionine on cephalosporin production results from its regulatory role, which can be duplicated by the non-sulphur analog norleucine. Eliminating cystathionine-gamma-lyase prevents the enhancing precursor effect of methionine on CPC production, and cystathionine-gamma-lyase overproduction in moderate doses increases CPC formation (Martin and Demain, 2002). When A. chrysogenum NCIM 1069 was used for the production of CPC, the yield of CPC decreased above optimum concentration of methionine $(0.4 \%)$. This decrease in production of antibiotic above certain concentration might be due to its toxic effect on the mold. Production of secondary metabolites is often subjected to the regulation by the readily metabolizable carbon sources and a decrease in the titre is noted. Even at higher concentration of carbon source with a slow uptake rate, which is beneficial for the production (sucrose and high $\mathrm{C} / \mathrm{N}$ ratio), the productivity of $\mathrm{CPC}$ decreased. This is probably because of accumulation of sucrose in the fermentation broth leading to the fragmentation and autolysis of the mold.

\section{CONCLUDING REMARKS}

The above studies conclude that for better yield of CPC, the nutritional requirement of mold should be at their optimal concentrations. It was found that ammonium sulphate as inorganic nitrogen source and methionine at the concentration of $0.4 \%$ are most suitable for higher yield of antibiotic. The variation in the $\mathrm{C} / \mathrm{N}$ ratio on the biosynthesis of $\mathrm{CPC}$ showed that a $\mathrm{C} / \mathrm{N}$ ratio of 8.0 is most suitable for maximum production of CPC. At higher concentrations (above optimal) the CPC biosynthesis decreased drastically and the cost economy will be increased.

\section{REFERENCES}

BOXER, George E. and EVERETT, Patricia M. Colorimetric determination of benzylpenicillin: colorimetric determination of total penicillins. Analytical Chemistry, 1949, vol. 21, p. 670-673.

BRAKHAGE, Axel A. Molecular regulation of $\beta$-lactam biosynthesis in filamentous fungi. Microbiology and
Molecular Biology Reviews, September 1998, vol. 62, no. 3, p. 547-585.

CRUZ, Antonio J.G.; ALMEIDA, Renate M.; ARAUJO, Maria Lucia G.C.; GIORDANO, Roberto C. and HOKKA, Carlos O. Modeling and simulation of cephalosporin $\mathrm{C}$ production in a fed batch tower type bioreactor. Applied Biochemistry and Biotechnology, 2001, vol. 93, no. 1-3, p. 537-549.

CRUZ, Antonio J.G.; PAN, Tai; GIORDANO, Roberto C.; ARAUJO, Maria Lucia G.C. and HOKKA, Carlos O. Cephalosporin $\mathrm{C}$ production by immobilized Cephalosporium Acremonium cells in a repeated batch tower bioreactor. Biotechnology and Bioengineering, January 2004, vol. 85, no. 1, p. 96-102.

DEMAIN, Arnold L. and NEWKIRK, Joanne F. Biosynthesis of cephalosporin C. Applied and Environmental Microbiology, July 1962, vol. 10, no. 4, p. 321-325.

DEMAIN, Arnold L. and ZHANG, Jinyou. Cephalosporin $\mathrm{C}$ production by Cephalosporium acremonium: the methionine story. Critical Reviews in Biotechnology, December 1998, vol. 18, no. 4, p. 283-294.

DEMAIN, Arnold L. and VAISHNAV, Preeti. Involvement of nitrogen-containing compounds in beta-lactam biosynthesis and its control. Critical Reviews in Biotechnology, April-June 2006, vol. 26, no. 2, p. 67-82.

ELLAIAH, P.; PREMKUMAR, J.; KANTHACHARI, P.V. and ADINARAYANA, K. Production and optimization studies of cephalosporin $\mathrm{C}$ by solid state fermentation. Hindustan Antibiotics Bulletin, February-November 2002, vol. 44, no. 1-4, p. 1-7.

ELANDER, R.P. Industrial production of beta-lactam antibiotics. Applied Microbiology and Biotechnology, June 2003, vol. 61, no. 5-6, p. 385-392.

KIM, Na Ri; LIM, Jung Soo; HONG, Suk In and KIM, Seung Wook. Optimization of feed conditions in a 2.5-1 fed batch culture using rice oil to improve cephalosporin $\mathrm{C}$ production by C. acremonium M25. World Journal of Microbiology and Biotechnology, July 2005, vol. 21, no. 5, p. 787-789.

KUNDU, Subir; MAHAPATRA, Amulya C.; NIGAM, Vinod Kumar and KUNDU, Kanika. Continuous production of cephalosporin $\mathrm{C}$ by immobilized microbial cells using symbiotic mode in a packed bed bioreactor. Artificial Cells, Blood Substitutes, and Immobilization Biotechnology, August 2003, vol. 31, no. 3, p. 313-327.

MARTIN, Juan F. and DEMAIN, Arnold L. Unraveling the methionine-cephalosporin puzzle in Acremonium chrysogenum. Trends in Biotechnology, December 2002, vol. 20 , no. 12 , p. 502-507. 
MILLER, Gail Lorenz. Use of dinitrosalicylic acid reagent for determination of reducing sugar. Analytical Chemistry, March 1959, vol. 31, no. 3, p. 426-428.

QUEENER, S.W. and ELLIS, L.F. Differentiation of mutants of Cephalosporium acremonium in complex medium: The formation of unicellular arthrospores and their germination. Canadian Journal of Microbiology, August 1975, vol. 21, no. 12, p. 1981-1996.

SHEN, Y.-Q.; HEIM, J.; SOLOMON, N.A. and DEMAIN, A.L. Repression of $\beta$-lactam production in Cephalosporium acremonium by nitrogen sources. The Journal of Antibiotics, May 1984, vol. 37, no. 5, p. 503-511.

SRIVASTAVA, Pradeep; NIGAM, Vinod Kumar and KUNDU, Subir. A comparative evaluation of cephalosporin $\mathrm{C}$ production in stirred tank reactor and air lift reactor. Indian Journal of Chemical Technology, November 1996, vol. 3, no. 6, p. 371-372.

SRIVASTAVA, Pradeep and KUNDU, Subir. Studies on cephalosporin $\mathrm{C}$ production in an air lift reactor using different growth modes of Cephalosporium acremonium. Process Biochemistry, June 1999, vol. 34, no. 4, p. 329333.

SILVA, Sibastiao A.; CRUZ, Antonio J.G.; ARAUJO, Maria Lucia G.C. and HOKKA, Carlos O. The effect of the addition of invert sugar on the production of cephalosporin $\mathrm{C}$ in a fed-batch bioreactor. Brazilian Journal of Chemical Engineering, December 1998, vol. 15, no. 4, p. 320-325.

SCHMITT, Esther K.; HOFF, Birgit and KUCK, Ulrich. Regulation of cephalosporin biosynthesis. Advances in Biochemical Engineering/Biotechnology, 2004, vol. 88, p. $1-43$.

TOLLNICK, C.; SEIDEL, G.; BEYER, M. and SCHUGERL, K. Investigations of the production of cephalosporin $\mathrm{C}$ by Acremonium chrysogenum. Advances in Biochemical Engineering/Biotechnology, 2004, vol. 86, p. 1-45.

VERMA, Ruchi; NIGAM, Vinod Kumar; KUNDU, Subir and GHOSH, Purnendu. Morphological differentiation and effect of seed inoculum on the production of CPC by Acremonium chrysogenum. Asian Journal of Experimental Sciences, 2006, vol. 20, no. 2, p. 275-280. 
APPENDIX

\section{FIGURES}

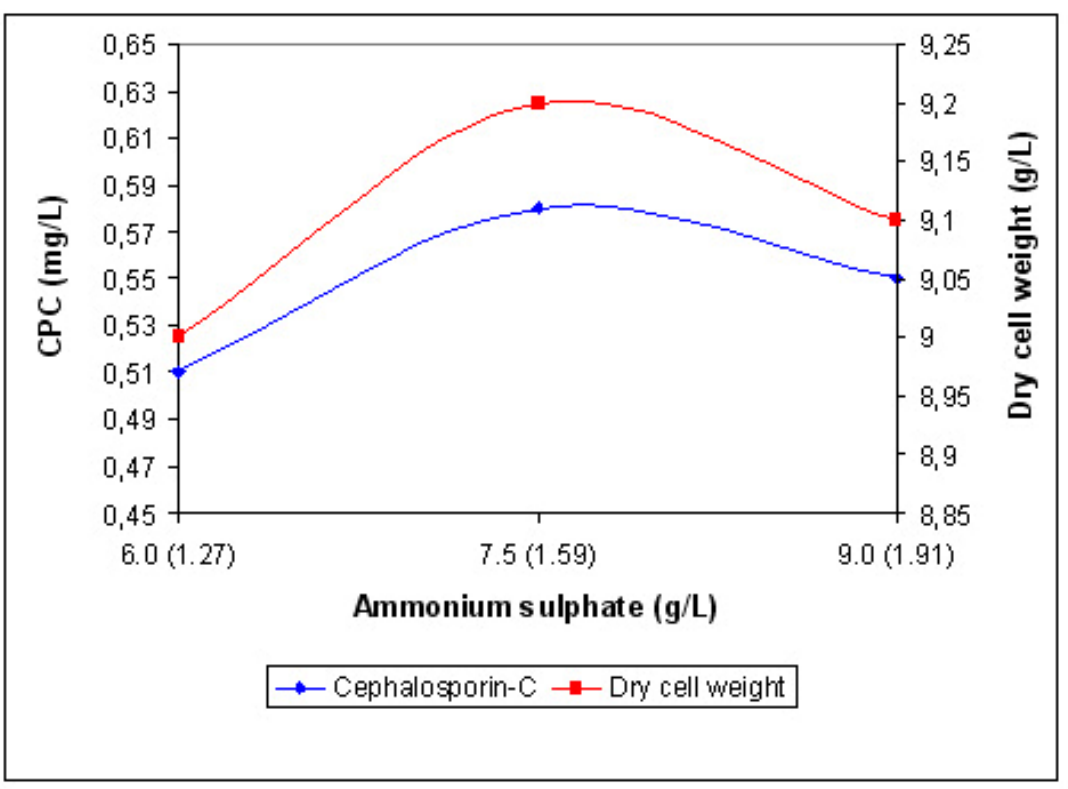

Figure 1. Effect of ammonium sulphate on the biosynthesis of CPC.

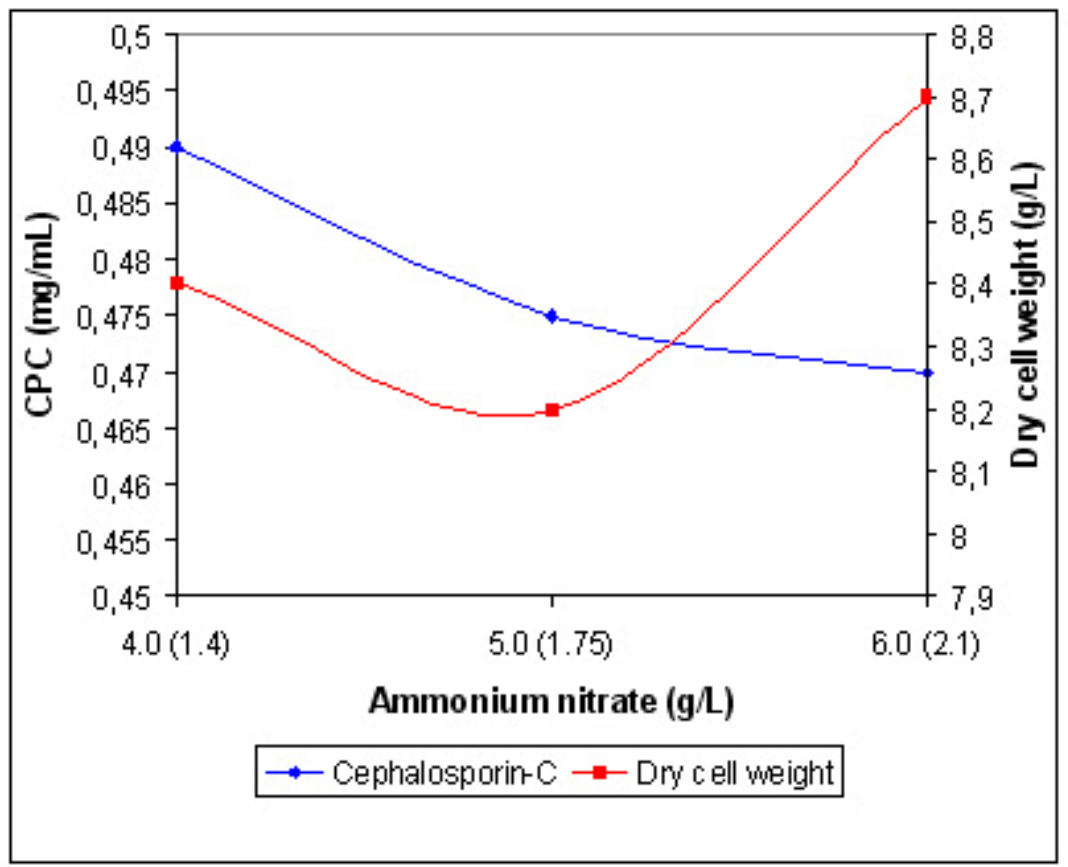

Figure 2. Effect of ammonium nitrate on the biosynthesis of CPC. 


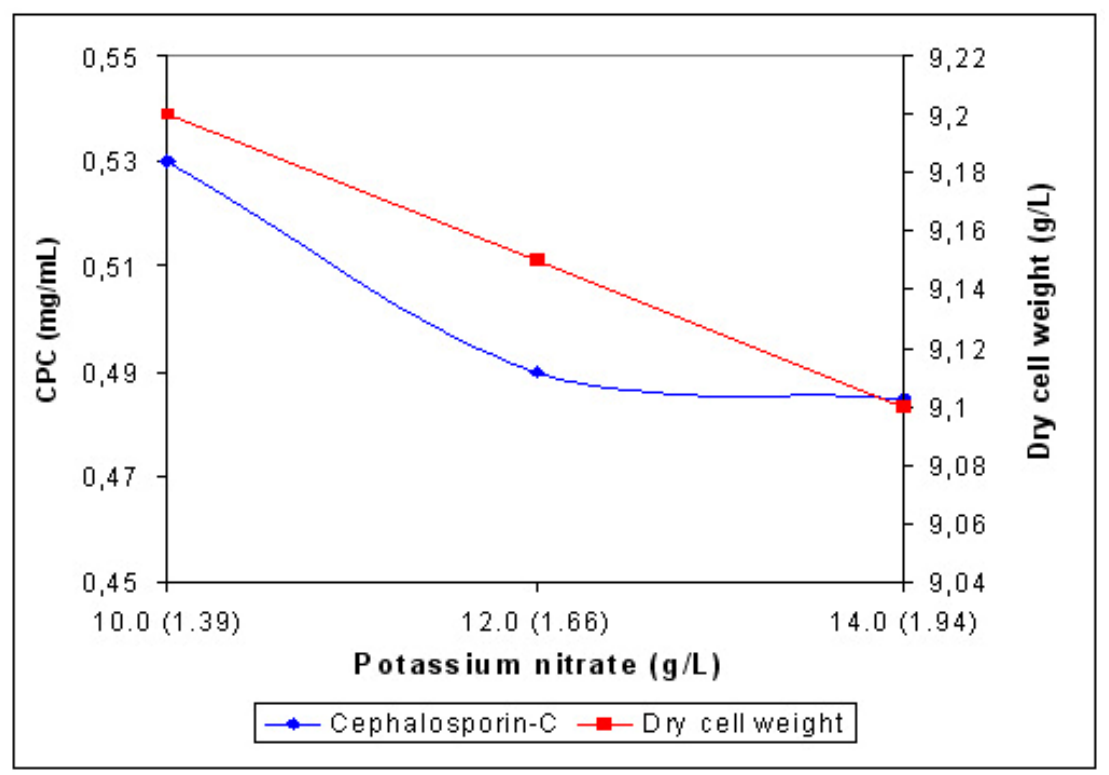

Figure 3. Effect of potassium nitrate on the biosynthesis of CPC.

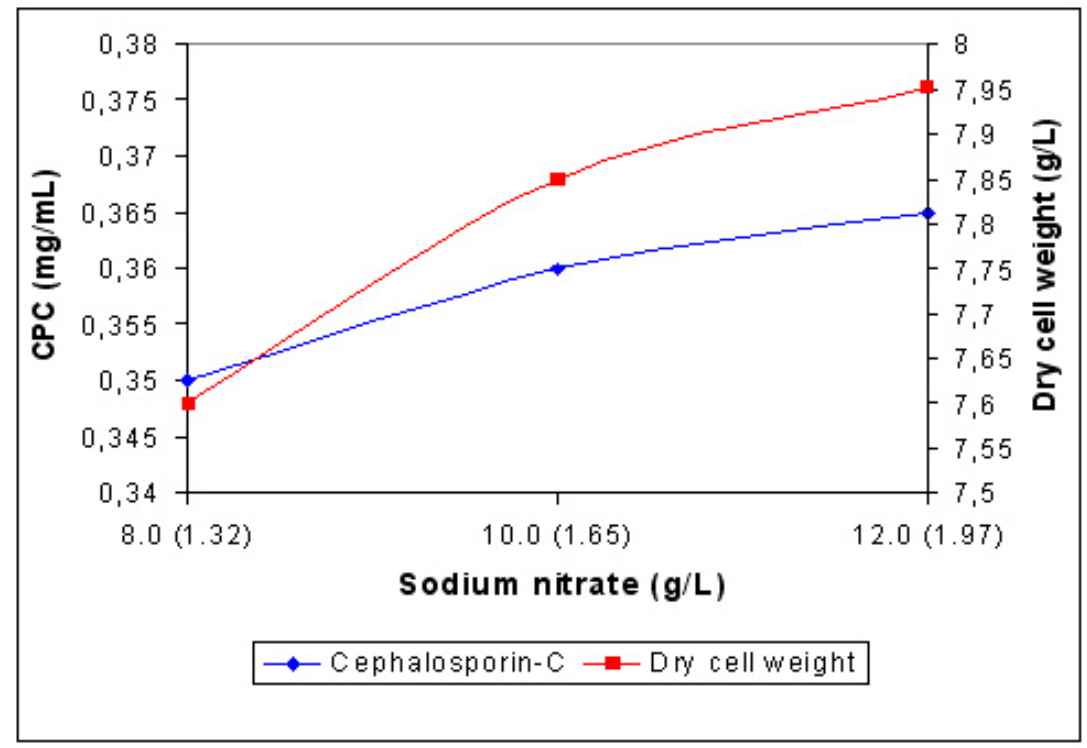

Figure 4. Effect of sodium nitrate on the biosynthesis of CPC. 


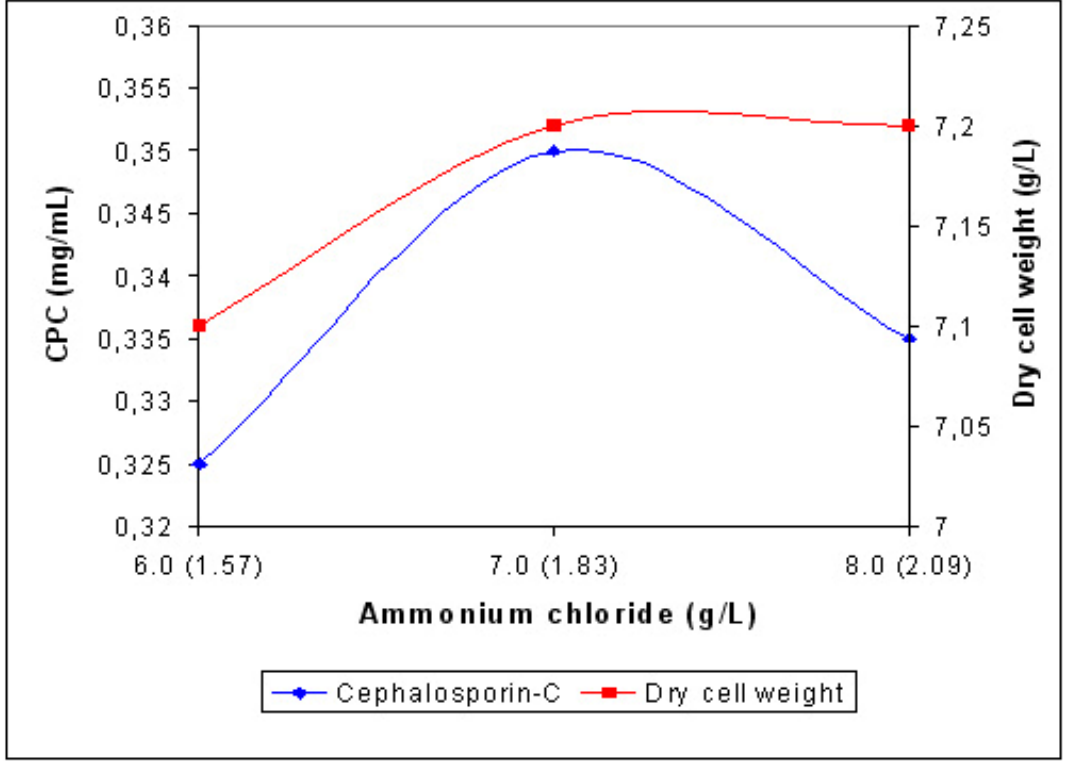

Figure 5. Effect of ammonium chloride on the biosynthesis of CPC.

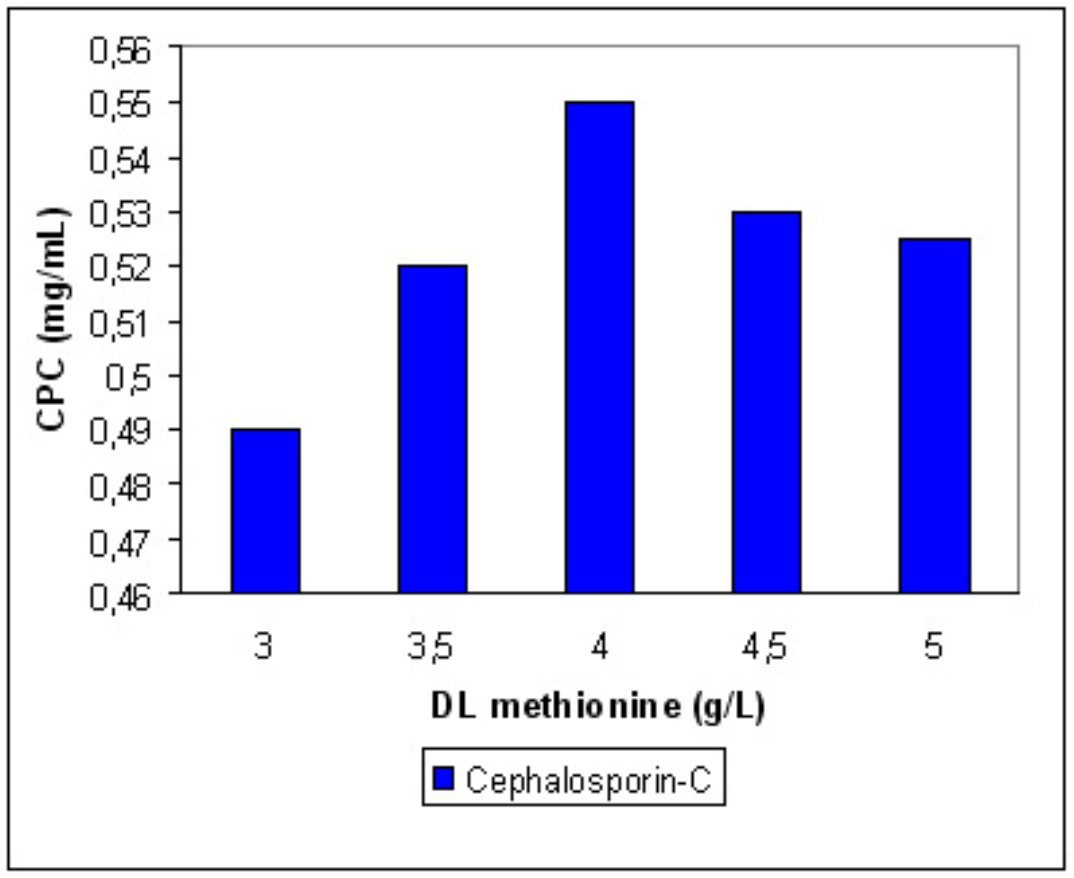

Figure 6. Effect of DL methionine on the biosynthesis of CPC. 


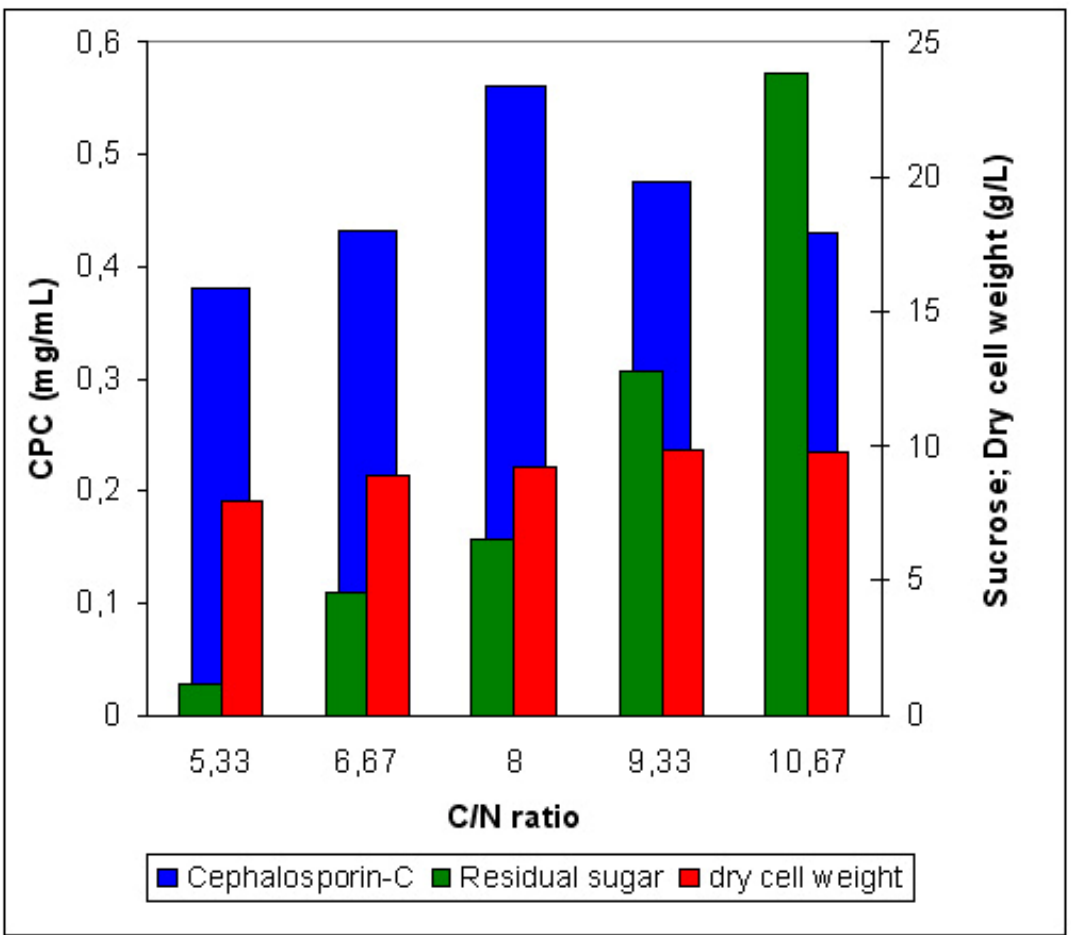

Figure 7. Effect of $\mathrm{C} / \mathrm{N}$ ratio on the biosynthesis of CPC. 


\section{TABLES}

Table 1. Batch fermentation of CPC in shake flask and in bioreactor.

\begin{tabular}{|c|c|c|c|c|c|c|}
\hline \multirow{2}{*}{ Time (Days) } & \multicolumn{2}{|c|}{ Residual sugar (g/L) } & \multicolumn{2}{c|}{ Dry cell weight (g/L) } & \multicolumn{2}{c|}{ CPC (mg/mL) } \\
\cline { 2 - 7 } & Shake flask & Bioreactor & Shake flask & Bioreactor & Shake flask & Bioreactor \\
\hline 0 & 31.5 & 32.0 & 1.08 & 1.24 & 0.00 & 0.00 \\
\hline 1 & 27.2 & 26.5 & 2.65 & 2.80 & 0.025 & 0.055 \\
\hline 2 & 22.4 & 20.0 & 4.96 & 5.26 & 0.148 & 0.22 \\
\hline 3 & 17.5 & 17.2 & 6.24 & 7.80 & 0.225 & 0.38 \\
\hline 4 & 14.0 & 13.4 & 7.14 & 8.82 & 0.322 & 0.482 \\
\hline 5 & 10.2 & 8.5 & 8.50 & 9.88 & 0.450 & 0.620 \\
\hline 7 & 6.8 & 4.6 & 8.60 & 10.6 & 0.518 & 0.696 \\
\hline & 4.9 & 2.7 & 8.32 & 10.4 & 0.532 & 0.640 \\
\hline
\end{tabular}

Table 2. A comparative evaluation of shake flask and bioreactor performance.

\begin{tabular}{|c|c|c|}
\hline Parameters & Shake flask & Bioreactor \\
\hline Working volume & $50 \mathrm{~mL}$ & $1.2 \mathrm{~L}$ \\
\hline Maximum cell biomass $(\mathrm{Xm}, \mathrm{g} / \mathrm{L})$ & 8.60 & 10.6 \\
\hline $\mathrm{CPC}(\mathrm{mg} / \mathrm{mL})$ & 0.53 & 0.69 \\
\hline Growth yield $(\mathrm{Yx} / \mathrm{s})$ & 0.282 & 0.32 \\
\hline Productivity $(\mathrm{Pr}, \mathrm{g} / \mathrm{L} / \mathrm{h})$ & $3.2 \times 10^{-3}$ & $4.8 \times 10^{-3}$ \\
\hline
\end{tabular}

